\title{
MITIGATING GROUP DISCUSSIONS IN DESIGN ACTIVITIES FOR JAPANESE HIGH STUDENTS DURING COVID-19 PANDEMIC
}

\author{
Leon LOH $^{1}$, Miki OGO ${ }^{2}$, Yanfang ZHANG ${ }^{1}$ and Noriko TAKANO ${ }^{1}$ \\ ${ }^{1}$ Kyushu University, Faculty of Design \\ ${ }^{2}$ Kyushu University, School of Design
}

\begin{abstract}
The purpose of this study is to clarify the factors that affect effective group discussions when using online whiteboard during face-to-face design activities for high school students in the classroom during the pandemic. Using a case study approach, the research was conducted at Fukusho High School in Fukuoka, Japan. Through the questionnaire survey, face-to-face discussions when combined with the use of online whiteboard, offers real-time verbal and non-verbal feedback that enabled effective group discussions during the design process. In addition, students' competencies in using digital devices may not influence the effectiveness of communications during group discussions and their motivations in using online whiteboard. The current findings may provide a useful hypothesis for further study to verify the correlations between students' competencies, effectiveness in communications when using online whiteboard during face-to-face discussions, and students' motivations in using online whiteboard.
\end{abstract}

Keywords: Design education, design activities, online whiteboard, communication skills

\section{INTRODUCTION}

The Sustainable Development Goals (SDGs) are central to achieving the 2030 Agenda for Sustainable Development adopted at the United Nations Sustainable Development Summit on 25 September 2015 [1]. In 2019, the SDGs Design School was established as a team in Kyushu University, Faculty of Design, to propagate SDGs awareness to the local community through design educational programmes. Adopting the design process used in industrial design, the SDGs Design School has been collaborating with Fukusho High School in Fukuoka city to develop design-based educational programmes into the Global Management Programme as part of the school curriculum to raise SDGs awareness in students [2]. In 2020, the Covid-19 pandemic has caused unprecedented impact to how education is being implemented in the classrooms. Since June 2020, schools in Japan have fully re-opened but continue to operate with a note of caution by adhering to new health and safety guidelines. Face-to-face lessons are allowed to be conducted. Before the Covid-19 pandemic, it was common for students to work in groups during design activities to share opinions and bounce off ideas by writing directly or putting Post-it Notes on flipchart papers. Due to the pandemic, working in groups with close proximity is not advisable. To mitigate the impact of maintaining social distancing during group discussions, distance learning techniques may be tweaked and applied to such circumstances.

Distance learning for design has been on-going for quite some time at university level [3]. Design studios in design education form an important platform for design conversations and discussions. Moving away from the physical environment, design conversations and discussion may take place in virtual studios [4][5][6][7]. Currently, most examples of virtual studios involve design students at university level.

Thus, the SDGs Design School faces a challenge to consider using distance learning techniques to implement meaningful and effective design programmes for high school students. The current challenges encountered by the SDGs Design School will be relevant for local and overseas institutes of higher education to consider the implications when implementing design programmes at high school level during the post-Covid-19 and with-Covid-19 conditions. The purpose of this study is to clarify the factors that affect effective group discussions when using online whiteboard during face-to-face design activities for high school students in the classroom during the pandemic. 


\section{LITERATURE REVIEWS}

\subsection{Synchronous and Asynchronous Online Mode}

As a form of communication, in general, computer-mediated communications (CMC) are described as communications, mediated by interconnected computers, between individuals or groups separated in space and/or time [8]. CMC can be categorised into synchronous (real-time) and asynchronous (delayed time). Synchronous online learning generally includes real-time dynamic social interactions. On the other hand, asynchronous online learning involves social interaction that are not real-time [9]. As for asynchronous online learning, students may participate in their own time through threaded video-based discussions and interactions that do not happen in real time, such as online discussion forums [10][11].

\subsection{Social Presence Theory}

With regards to interactions, communications and collaborative learning during online learning, the concept of social presence may be used to guide the evaluation on the effectiveness online learning.

First introduced by Short, Williams \& Christie [12], the social presence theory describes social presence as the extent to which a person viewed a social interaction in a technology mediated interaction as authentic. Social presence involves two key factors, intimacy, and immediacy. Intimacy is influenced by factors such as physical distance, eye contact, smiling, and personal topics of conversation. Immediacy is a measure of the psychological distance which a communicator puts between himself/herself and the object of the communication. Immediacy may be conveyed non-verbally or verbally. Non-verbal factors may be conveyed by such as physical proximity, formality of dress, and facial expression.

Building on the conceptualization of the social presence theory, Gunawardena \& Zittle defined intimacy as the quality of interpersonal relationship between individuals in the technology mediated interaction [13]. Thus, humour and sharing of personal experiences may improve the quality of social presence. In the aspect of immediacy, it was believed that the longer it took an individual to receive a response, the less social presence they perceived and the less engaged they were likely to be.

\subsection{Technology Acceptance Model}

Technology acceptance model (TAM) has been widely used to study user acceptance of internet-based learning systems. The TAM assumes that the perceived ease of use and usefulness of online learning system (also include online discussion forums) are major influences on an individual's attitude towards such as system; and thus, are related to the intention to use it and in turn, to its actual use [14]. According to Davis, Bagozzi \& Warshaw, the perceived ease of use can be referred to the degree that a person perceives the use of the system is effort free [15]. In addition, the perceived usefulness can be referred to as the degree a person perceives the use of the system would enhance job performances. The perceive usefulness is dependent on the perceive ease of use and the intention of using the system. Adding on to the TAM, perceived ease of use and usefulness may be influenced by external factors such as motivation, academic background, income level, age, and user's experience [16][17][18].

\section{RESEARCH METHODOLOGY AND IMPLEMENTATION}

\subsection{Research Questions}

While online learning techniques may operate using synchronous and asynchronous environment, the current study operates in a face-to-face environment where offline and online real-time social interactions may be achieved. Under this context, the research questions are as follows.

1) Can technology such as online whiteboard contribute to the effective communication among high school students during face-to-face design activities?; and

2) What are the factors that may affect students in communicating their opinions or ideas during design activities when using the online whiteboard?

\subsection{Research Approach and Method}

The current study employed a qualitative research approach where a case study method is used as an educational tool for understanding pedagogical processes as described by Aaltio and Heilmann [19]. The current study was conducted at Fukusho High School in Fukuoka city, Japan. To clarify the two research questions, the SDGs Challenge Project in Global Management Programme was used as the 
platform for research. The considerations for selecting Fukusho High School as target school was based on the following considerations: a) school is a typical public high school and b) consists of mixed student academic abilities. Using a typical Japanese high school will position the outcomes of this study to be much more applicable to a broader range of high schools with similar profile as Fukusho High School.

\subsection{Participants, Research Design, and Implementation}

Participants were high school students (about 18-year-old) with no prior design experience. Participants formed the sub-units and data from each sub-unit was pooled to answer the research questions within this case study. The data is collected through a questionnaire survey that focus on opinions and attitudes. The questionnaire is structured to first find out students' personal competencies in using digital devices. Next, the students' motivation in using the online whiteboard is surveyed as their motivation may influence their perception in the usefulness of the platform which in turn implicates enhanced performance in the activities as mentioned in TAM. Finally, students perceived effectiveness of the online whiteboard during group discussions is surveyed. Refer to Table 1 . The survey was conducted after the completion of the SDGs Challenge Project with a collection rate of 24 out of 28 students in the class.

Table 1. Question items in each part of the questionnaire survey

\begin{tabular}{|c|c|c|}
\hline Key Focus & $\begin{array}{l}\text { Questionnaire Survey Items } \\
\end{array}$ & Question Types \\
\hline $\begin{array}{l}\text { Part 1: Individual } \\
\text { competency in } \\
\text { using ICT }\end{array}$ & $\begin{array}{l}\text { Q1: I am good at using digital devices } \\
\text { Q1-1: Reasons for Q1 }\end{array}$ & $\begin{array}{l}\text { Q1.5-point Likert Items from Strongly } \\
\text { disagree (1) to Strongly agree (5) } \\
\text { Q1-1. Open-ended }\end{array}$ \\
\hline $\begin{array}{l}\text { Part 2: Personal } \\
\text { motivation in } \\
\text { using online } \\
\text { whiteboard during } \\
\text { discussions }\end{array}$ & $\begin{array}{l}\text { Q2: I would like to continue to use apps like MIRO in the } \\
\text { future when doing group work in the corona disaster. } \\
\text { Q3: I would like to continue to use apps like MIRO in my } \\
\text { classes in the future when we do group work, even if the } \\
\text { corona pandemic has subsided. }\end{array}$ & $\begin{array}{l}\text { Q2 \& Q3. 5-point Likert Items from } \\
\text { Strongly disagree (1) to Strongly agree } \\
\text { (5) }\end{array}$ \\
\hline $\begin{array}{l}\text { Part 3: } \\
\text { Effectiveness } \\
\text { related }\end{array}$ & $\begin{array}{l}\text { Q4: We were able to conduct discuss with social distance in } \\
\text { mind. } \\
\text { Q5: We had a lively discussion while using MIRO. } \\
\text { Q5-1: Reasons for Q5 }\end{array}$ & $\begin{array}{l}\text { Q4 \& Q5. 5-point Likert Items from } \\
\text { Strongly disagree (1) to Strongly agree } \\
\text { (5) } \\
\text { Q5-1. Open-ended }\end{array}$ \\
\hline
\end{tabular}

As face-to-face lessons are allowed to be conducted, one of the ways to reduce close contact is to introduce the use of online whiteboards, such as Miro, to facilitate face-to-face group discussions. Miro was selected as the tool because:

a. sketching and notes during the discussion can be shared in real-time without much time lag

b. the application can be easily installed onto tablets such as iPads

c. ease of use and variety of functions that are useful during group discussions

To use the online whiteboard, iPads or Windows tablets are used as the stylus pens enable students to write and sketch in Miro more easily than laptops. Students would work in groups of 5 or 6 to identify design problems within the community and then propose the most appropriate design concept. The brief outline of the programme plan can be presented in Table 2. As some students might not be as IT savvy as others, usage instructions and templates for online whiteboard were provided before each online activity. A short briefing was also conducted before each online activity. During the project, students would switch between off-line and a hybrid of off-line and online activities. Off-line activities were mainly individual assignments where students would write their findings, reflections and ideas on a worksheet booklet developed for this project. The hybrid of off-line and online activities were mainly in-person group discussions. Refer to Figure 1.

Table 2. A brief lesson plan for the SDGs Challenge Project

\begin{tabular}{|c|c|c|c|}
\hline \multicolumn{4}{|c|}{ SDGs Challenge Project Programme Plan } \\
\hline Day & & Lesson Plan & Remarks \\
\hline $\begin{array}{l}\text { Day } 1 \\
17 \text { August } 2020 \\
\text { Lesson Duration: } \\
3 \mathrm{Hr}\end{array}$ & 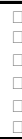 & $\begin{array}{l}\text { Each student identification of design problems in the community } \\
\text { Sharing of design problems to group members } \\
\text { Each group to discussion and select on design problem to engage } \\
\text { Group discussion to deepen understanding of problem } \\
\text { Identify existing solutions related to the selected problem } \\
\text { Present selected problems and findings on existing solutions }\end{array}$ & $\begin{array}{l}\text { Students may } \\
\text { work individually } \\
\text { or in group }\end{array}$ \\
\hline $\begin{array}{l}\text { Day } 2 \\
18 \text { August } 2020 \\
\text { Lesson Duration: } \\
3 \mathrm{Hr}\end{array}$ & 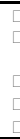 & $\begin{array}{l}\text { Each student explores ideas to solving the problem } \\
\text { Each student critiques his/her own design ideas to gain deeper } \\
\text { understanding on solving the problem } \\
\text { Sharing of design ideas to group members } \\
\text { Discussion and selection of an idea to work on further details } \\
\text { Conceptualise the idea and present to the class }\end{array}$ & $\begin{array}{l}\text { Students may } \\
\text { work individually } \\
\text { or in group }\end{array}$ \\
\hline $\begin{array}{l}\text { Day } 3 \\
19 \text { August } 2020 \\
\text { Lesson Duration: } \\
3 \mathrm{Hr}\end{array}$ & & $\begin{array}{l}\text { Seeking other point of views on selected idea } \\
\text { Improvement of idea } \\
\text { Creation of prototype or concept poster } \\
\text { Presentation of final concept }\end{array}$ & $\begin{array}{l}\text { Students may } \\
\text { work individually } \\
\text { or in group }\end{array}$ \\
\hline
\end{tabular}




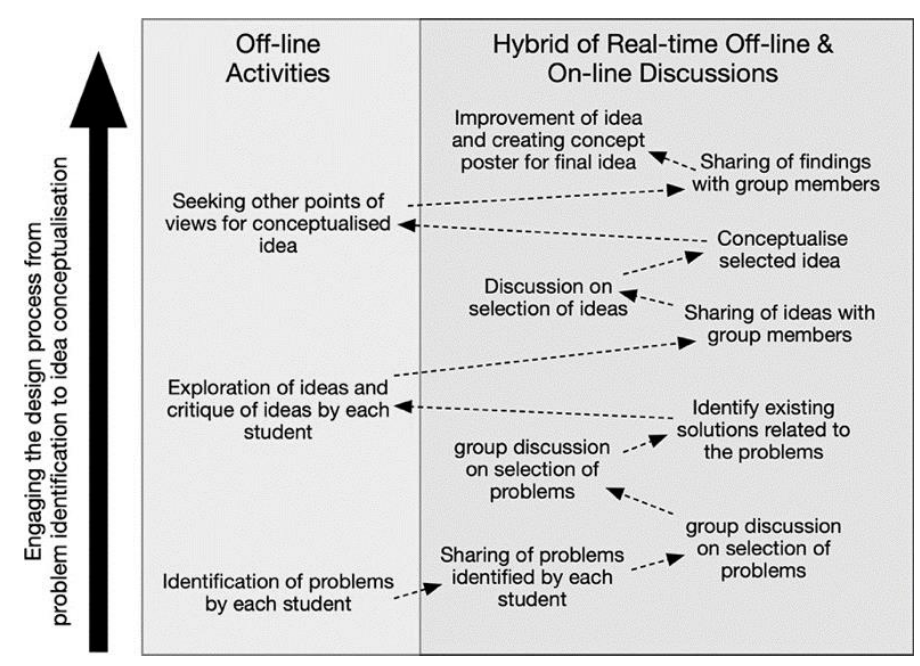

Figure 1. The switch between off-line activities and a hybrid of real-time off-line and online discussions

\section{FINDINGS}

The responses for the questionnaire are presented in Figure 2 and Table 3. When asked about their competencies in using digital devices, refer to Q1 in Figure 2, about 45\% of the students agreed that they are competent in using digital devices. Some of the main reasons are due to the exposure in using computers at an early age and opportunities to using ICT devices. Although almost $30 \%$ of the students are neutral about their competencies in using digital devices, almost all of them felt that they are somewhat not knowledgeable or not good at using computer devices. About $25 \%$ of the students felt that they are not competent in using digital devices. Some of the main reasoning are due to the lack of exposure or opportunities to use computers. In general, slightly more than $50 \%$ of the students believed that they are somehow not good at using digital devices.

Although it may be deducted that there are more students who are not very competent in using digital devices, more than half of them have indicated positively about using Miro and also in future group activities, refer to Q2 and Q3 in Figure 2. This may suggest that students' competencies may not have a strong influence on their motivations in using online whiteboard during face-to-face group activities. In addition, almost $80 \%$ of the students indicated that they were able to conduct discussions with social distancing on mind, based on responses for Q4. At the same time, over $90 \%$ of the students had indicated that the discussions were lively when using Miro, refer to Q5, which may suggest effectiveness. Based on the responses for Q5-1, the factors that influence effective communication may be consolidated in Table 3 under three major themes. As such, it may be assumed that most students perceived to achieve effective communications while using Miro during face-to-face group activities without gathering in close proximity. In addition, the current findings may also suggest that even though most students may not be very competent in using digital devices, this may not influence their motivation in using online whiteboard and the perceive effectiveness of the online whiteboard for group discussions.

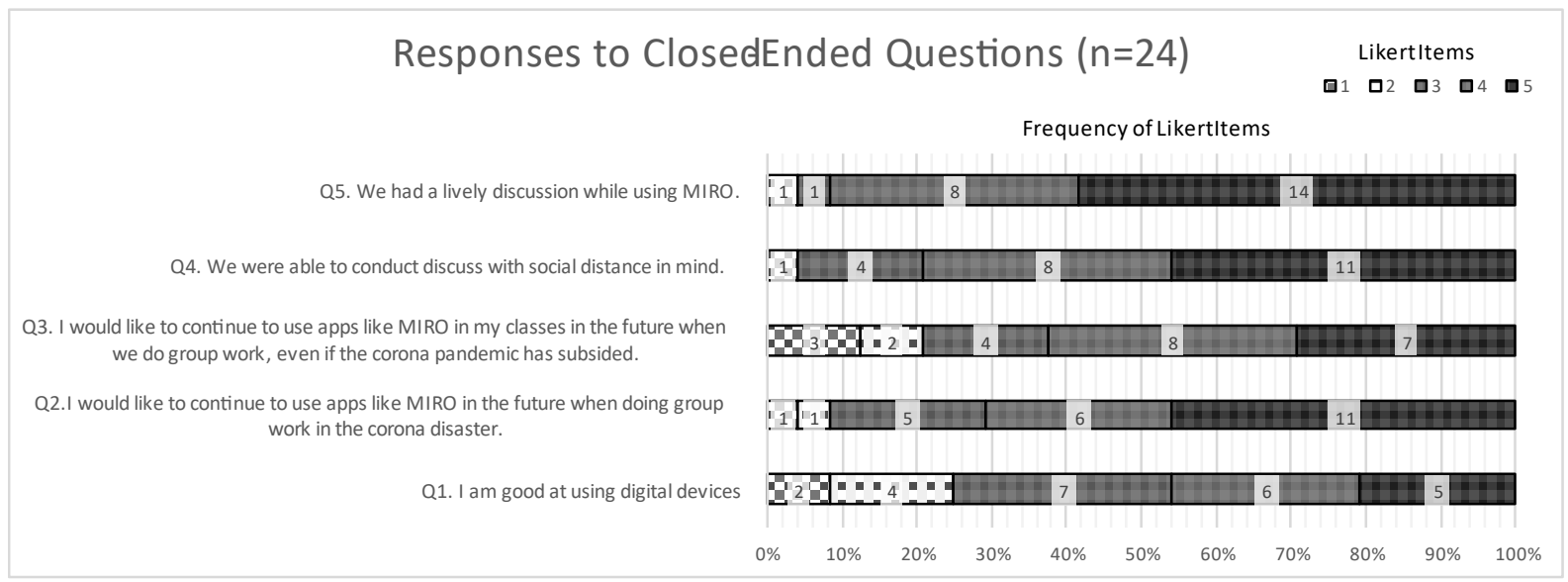

Figure 2. Responses of students for Question 1 to 5 
Table 3. Open-ended responses in Q5-1

\begin{tabular}{|c|c|c|}
\hline Main themes & & Key points gathered with respect to students' perception to Q5 \\
\hline $\begin{array}{l}\text { Technical Issues } \\
\text { related }\end{array}$ & $\square$ & Some students encountered disconnection from the online whiteboard at times. \\
\hline Usability related & $\begin{array}{l}\square \\
\square \\
\square \\
\square\end{array}$ & $\begin{array}{l}\text { Requires time to get used to using the application; especially when constant switching between } \\
\text { offline and online activities. } \\
\text { Online whiteboard is easy to use and has variety of functions. } \\
\text { The post-it function within the online whiteboard is useful for gathering opinions. } \\
\text { The process of face-to-face discussion, coupled with the use of online whiteboard is useful for } \\
\text { students to organize their thoughts. } \\
\text { Within the online whiteboard, students can see many opinions at once. }\end{array}$ \\
\hline $\begin{array}{l}\text { Effectiveness in } \\
\text { communications } \\
\text { related }\end{array}$ & $\begin{array}{l}\square \\
\square \\
\square \\
\square \\
\square \\
\square \\
\square\end{array}$ & $\begin{array}{l}\text { For students who are used to using the application, they may voice out their opinions verbally. If } \\
\text { not, they may remain silent during the discussions. } \\
\text { For students who are not good at voicing out their opinions, the online whiteboard allowed them } \\
\text { to express their views. } \\
\text { While using the online whiteboard, many decisions can be made during the discussion. } \\
\text { The content in the online whiteboard can generate lively conversations. } \\
\text { Ideas can be exchanged effectively as information can be shared through online whiteboard } \\
\text { concurrently during the discussions. } \\
\text { While maintaining social distancing, ideas can still be exchanged effectively. }\end{array}$ \\
\hline
\end{tabular}

\section{Discussions}

The approach in this study combined face-to-face design discussions and online synchronous mode of social interactions via online whiteboard, such as Miro. As discussions are done face-to-face, real-time immediate verbal and non-verbal feedback, may provide students with little lag-time in terms of communicating their ideas to each other. In a way, this condition may satisfy factors related to intimacy and immediacy under the social presence context, which influence the evaluation of online learning. Furthermore, conversations in design are important to generate discussion on a certain thought process [20]. Thus, by enabling students to conduct conversations in design, and providing the conditions for intimacy and immediacy in these conversations may contribute to students' positive evaluation on the effectiveness of communication when using online whiteboard during group discussion.

Currently, to reduce social contact within the school during Covid-19, lessons may be done remotely through synchronous, asynchronous or hybrid modes. This study presents an example of face-to-face design activities conducted without close gathering. Perhaps, to allow effective communication in activities similar to current study, the following suggestions may be considered. Firstly, the online whiteboard should contain functions that are easy to use and allow students to consolidate opinions. Secondly, teachers may need to set routines for students when conducting group discussions when using the online whiteboard. This is because, the constant switching between offline and online activities may cause confusion to students during the group discussions. It may be necessary for teachers to allocate sufficient time for students to write their opinions in the online whiteboard and follow by off-line faceto-face group discussions. Although students' competencies may not seem to influence their motivation in using the online whiteboard and their perceived effectiveness of group discussion in current format, more support in terms of training sessions before lesson activities in using online whiteboards may be necessary. Especially if online learning in design lessons is to stay for an unforeseeable future.

As limitations to this study, the current participant size is too small to clarify any statistical correlations between the different Likert item variables in the survey. Thus, the current assumptions that students' competencies in using digital devices may not influence their motivations in using online whiteboard and their perceived effectiveness of communication through online whiteboard will offer as hypothesis for further quantitative study. To study more deeply into the effectiveness of online whiteboards during face-to-face design discussions, a more rigorous study may need to be done by engaging students into complex projects that include complex design drawings and modelling processes.

\section{CONCLUSIONS}

As a conclusion, face-to-face design discussions when combined with the use of online whiteboard, provide students with real-time verbal and non-verbal feedback which offer effective group discussions during design activities. In addition, students' ability to use digital devices may not have direct influence on the perceived effectiveness of group discussions and their motivation to use online whiteboard during design discussions. To facilitate effective communications in activities similar to the current study, some suggestions such as choosing an easy-to-use online whiteboard with functions that allow ideas to be consolidated, setting up instructional routines in group discussions and providing training sessions before lessons activities may be necessary. 


\section{ACKNOWLEDGEMENTS}

The authors would like to extend their appreciation to the principal and teachers of Fukusho High School for this study. This work was supported by JSPS KAKENHI Grant Number JP18K13168.

\section{REFERENCES}

[1] United Nations (2015). Transforming our World: The 2030 Agenda for Sustainable Development. Retrieved May 22, 2021, from https://sdgs.un.org/publications/transforming-our-world-2030agenda-sustainable-development-17981

[2] Loh W. L., Shimomura M., and Zhang Y. F. (2020). Unlocking Creative Minds to Engage SDGs Through Design Education in Japanese High School. In Proceedings of the 22nd International Conference on Engineering and Product Design Education (E\&PDE 2020). https://doi.org/10.35199/EPDE.2020.16

[3] Jones D. (2020, March 14). Distance and online design education - a (not so) quick introduction. Distance Design Education. https://distancedesigneducation.com/2020/03/14/example-post-2/

[4] Lotz N., Jones D., and Holden G. (2019). OpenDesignStudio: Virtual Studio Development over a Decade. In Proceedings of DRS Learn X Design 2019: Insider Knowledge. doi: 10.21606/learnxdesign.2019.01083

[5] Venkatesh A. and Ma H. (2019). Tacit Learning in an Extended Interior Design Studio. In Proceedings of DRS Learn X Design 2019: Insider Knowledge. doi: 10.21606/learnxdesign.2019.01028

[6] Hilton C. (2019). The Evolution of the Design Studio: Hybrid Learning Spaces. Proceedings of DRS Learn X Design 2019: Insider Knowledge. doi: 10.21606/learnxdesign.2019.01089

[7] Lauche K., Bohemia E., Badke-Schaub P., Wilson C., Langeveld L., Conner C., and Titley W. (2007). Distributed design studio: Evaluation of the three way collaboration. In Proceedings of the 22nd International Conference on Engineering and Product Design Education (E\&PDE 2007). pp. 619-624.

[8] Luppicini R. (2007). Review of computer mediated communication research for education. Instructional Science, 35(2), 141-185.

[9] Dahlstrom-Hakki I., Alstad Z., and Banerjee M. (2020) Comparing synchronous and asynchronous online discussions for students with disabilities: The impact of social presence. Computers \& Education, 150, article 103842. https://doi.org/10.1016/j.compedu.2020.103842

[10] Ibid.

[11] Abdu Saeed M. and Ghazali K. (2017). Asynchronous group review of EFL writing: Interactions and text revisions. Language Learning \&Technology, 21(2), 200-226.

[12] Short J., Williams E., and Christie B. (1976). The social psychology of telecommunications. London: John Wiley \& Sons.

[13] Gunawardena C. N. and Zittle F. J. (1997). Social presence as a predictor of satisfaction within a computer-mediated conferencing environment. American Journal of Distance Education, 11(3), 8-26.

[14] Davis F., Bagozzi R., and Warshaw P. (1989), User acceptance of computer technology: a comparison of the two theoretical models, Management Science, 35(8), 982-1003.

[15] Ibid.

[16] Saade R. and Bahli B. (2005). The impact of cognitive absorption on perceived usefulness and perceived ease of use in on-line learning: an extension of the technology acceptance model. Information and Management, 42, 317-327.

[17] Karahanna E. and Straub D. W. (1999). The psychological origins of perceived usefulness and ease-of-use. Information and Management, 35, 237-250.

[18] Porter C. E. and Donthu N. (2006). Using the technology acceptance model to explain how attitudes determine Internet usage: The role of perceived access barriers and demographics. Journal of Business Research, 59, 999 - 1007.

[19] Aaltio I. and Heilmann P. (2010). Case study as a methodological approach. In A. J. Mills, G. Durepos \& E. Wiebe (Eds.), Encyclopaedia of Case Study Research (pp.66-76). California: Sage Publications, Inc.

[20] Venkatesh A. and Ma H. (2019). 